\title{
FUNGSI MUSIK DALAM UPACARA PERAYAAN RITUAL THAIPUSAM ETNIS HINDU TAMIL DI BANDA ACEH
}

\author{
Rika Wirandi ${ }^{1^{*}}$, Maghfihrah Murni B. P. ${ }^{{ }^{*}}$ \\ Program Studi Seni Karawitan Program Studi Seni Tari \\ Jurusan Seni Pertunjukan \\ Institut Seni Budaya Indonesia Aceh \\ Jl. Transmigrasi, Gampong Buket Meusara, Kec. Kota Jantho, Kab. Aceh Besar, Kode Pos 23911 \\ Aceh. Indonesia \\ Email: rikawirandi@isbiaceh.ac.id,maghfhirahmurni@isbiaceh.ac.id
}

\begin{abstract}
Abstrak
Thaipusam adalah upacara perayaan yang diselenggarakan secara sakral dalam bentuk prosesi ritual doa dan prosesi araka-arakan arca Dewa Murugan yang diselenggarakan setiap tahun oleh masyarat etnis Hindu Tamil di Banda Aceh. Ritual ini dilangsungkan pada bulan Thai menurut kalender Hindu Tamil, sebagai bentuk penghormatan Dewa Murugan atas kemenangannya memerangi kejahatan. Upacara perayaan ini juga sebagai ajang untuk menunaikan nazar dan menyucikan diri bagi peserta ritual -- yang disertai atraksi menusukkan benda-benda tajam ke beberapa bagian tubuh tertentu seperti, lidah, bibir, pipi, dahi, punggung, serta bagian tubuh lainnya. Upacara perayaan ini menghadirikan permainan musik perkusi pada saat prosesi arak-arakan. Selain memiliki fungsi yang jamak dalam konteks upacara perayaannya, musik ensambel perkusi dalam arak-arakan juga diyakini memiliki efek tersendiri bagi peserta ritual. Nyanyian keagamaan dan ensambel musik perkusi dalam upacara perayaan tersebut secara sekilas memang tampak sebagai unsur pemeriah ritual semata. Namun, lebih jauh, ensambel musik perkusi tersebut dinilai berperan dalam memengaruhi spiritualitas pelaku ritual hingga mengantarnya ke pada kondisi kusyuk, hingga trance saat melakukan atraksi tindik tubuh. Tujuan penelitian ini untuk melihat fungsi musik dalam upacara perayaan Ritual Thaipusam serta dalam memengaruhi tingkat spiritualitas peserta ritual. Metode penelitian yang dipakai adalah metode penelitian kualitatif yang dilakukan dalam beberapa tahapan, di antaranya: studi literatur dan wawancara mendalam. Pendekatan yang digunakan dalam penelitian ini adalah teori fungsi musik dari Alan P. Merriam dan pendekatan tentang musik dan trance yang dikemukakan oleh Gilbert Rouget. Hasil penelitian ini menyatakan bahwa, setidaknya terdapat empat fungsi musik yang teramati dalam penelitian ini, di antaranya: fungsi pemeriah dan hiburan; fungsi ekspresi budaya; fungsi pengabsahan upacara ritual; dan fungsi integritas kelompok masyarakat. Di sisi lain, bagi pendukung ritual - dalam hal ini peserta nazar, musik berfungsi sebagai penguat spiritual mereka dalam menunaikan nazar.
\end{abstract}

Kata Kunci: fungsi musik, thaipusam, Banda Aceh

\begin{abstract}
Thaipusam is a celebration ceremony held sacredly in the form of a prayer ritual procession and the procession of the Lord Murugan statues which is held annually by the Tamil Hindu ethnic community in Banda Aceh. This ritual is held in the Thai month according to the Hindu Tamil calendar, as a form of respect for Lord Murugan for his victory in fighting evil. This celebration ceremony is also a place to fulfill vows and purify themselves for ritual participants - which is accompanied by the attraction of stabbing sharp objects into certain body parts such as the tongue, lips, cheeks, forehead, back, and other body parts. This celebration ceremony includes percussion music at the time of the procession. In addition to having multiple functions in the context of the celebration ceremony, percussion ensemble music in the procession is also believed to have its own effect on ritual participants. Religious songs and percussion music ensembles in the celebration ceremony at first glance do appear to be mere elements of ritual celebration. However, furthermore, the percussion music ensemble is considered to play a role in influencing the spirituality of the ritual performer to lead him to a state of stupor, to trance when performing body piercing attractions. The purpose of this study was to examine the function of music in the Thaipusam Ritual celebration ceremony as well as in influencing the spirituality level of the ritual participants. The research method used is a qualitative research method which is carried out in several stages, including: literature study and in-depth interviews. The approach used in this research is the theory of music function from Alan P. Merriam and the approach to music and trance proposed by Gilbert Rouget. The results of this study indicate that, at least there are four functions of music observed in this study, including: celebratory and entertainment functions; function of cultural expression; the function of legitimizing ritual ceremonies; and function of community group integrity.
\end{abstract}


On the other hand, for ritual supporters - in this case the votive participants, music serves as a spiritual reinforcement for them in fulfilling their vows.

Keywords: music function, thaipusam, Banda Aceh.

\section{PENDAHULUAN}

Thaipusam adalah upacara keagamaan tahunan yang diselenggarakan etnis Hindu Tamil di berbagai daerah di dunia. Di indonesia, upacara perayaan tersebut dilangsungan di berbagai beberapa daerah yang menjadi tempat etnis Tamil.

Upacara dalam bentuk ritual sakral ini diselenggarakan sebagai bentuk penghormatan kepada dewa Murugan oleh komunitas Hindu Tamil di Kuil Palani Andawer, Banda Aceh.

Thaipusam dirayakan pada bulan 'Thai' bulan kesepuluh dalam kalendar Tamil (Dwi, 2019). Upacara keagamaan ini biasa dilakukan saat purnama pada bulan kesepuluh ("thai") dalam penanggalan Tamil, antara bulan Januari-Februari tahun Masehi (Mogot, 2019). Bagi komunitas Hindu Tamil di Banda Aceh, penyelenggaraan Thaipusham bisanya diselenggarakan pada bulan Februari hingga Maret, setelah berlangsungnya penyelenggaraan di berbagai dearah di Kota Medan dan sekitarnya.

Thaipusam adalah upacara ritual yang diselenggarakan secara sakral dalam beberapa rangkaian prosesi ritual yang sakral. Upacara ini dibalut dengan perayaan meriah yang ditandai dengan prosesi arak-arakan. Bagi sebagian masyarakat Hindu Tamil, ritual tersebut juga menjadi sarana untuk menunaikan nazar dan menyucikan diri bagi individu-invidu yang memiliki nazar dengan disertai atraksi menusukkan benda-benda tajam ke beberapa bagian tubuh tertentu seperti, mulut, pipi, punggung, serta bagian tubuh lainnya oleh yang punya nazar. Pemaknaan lain dalam ritual Thaipusam ini adalah sebagai sebuah perayaan dalam menunaikan nazar serta memohon ampun atas dosa-dosa yang telah diperbuat selama hidup (Riyaf \& Hasanah, 2016).

Dalam ritual yang dijalaninya, peserta upacara biasanya menyakiti diri dengan cara menusuk bagian dari tubuh mereka dengan benda. Bermacam jarum, tombak kecil dan kail dikaitkan ke tubuh mereka. Sebagian peserta ada juga yang menusuk wajahnya dengan anak panah ("vel"), yang merupakan simbol senjata yang diberikan Dewa Syiwa kepada anaknya (Murugan) untuk mengalahkan yang jahat (evil). Dengan melukai diri, para pelaku upacara meyakini telah melakukan pengorbanan yang melambangkan penyesalan akan dosa yang telah diperbuatnya, sebagai simbol dari kemenangan kebaikan atas kejahatan (Mogot, 2019).

Upacara Thaipusam menghadirkan pertunjukan musik pada saat arak-arakan. Musik ensambel perkusi dan nyanyian keagamaan dilantunkan secara bersamaan sejak dimulainya upacara yang ditandai dengan doa sakral oleh beberapa orang pendeta di kuil Palani Andawer, di Kota Banda Aceh. Iringan musik perkusi dalam upacara perayaan Ritual Thaipusam secara sekilas memang tampak sebagai unsur pemeriah ritual semata. Namun, lebih jauh, ensambel musik tersebut berperan dalam memengaruhi spiritualitas para pelaku dalam memaknai dan menjalani ritual, serta memiliki fungsi tersendiri terhadap ritual tersebut.

Gilbert Rouget berpandangan bahwa, musik perkusi merupakan instrumen yang paling mudah memengaruhi pendengaran manusia karena memiliki efek neurogikal yang membuat setiap pendengarnya dapat mencapai kondisi khusyuk, bahkan trance. Kondisi yang dimaksud hampir sama dengan kondisi yang dialami oleh peserta nazar yang tidak merasakan sakit dan pendarahan pada bagian tubuh tertentu saat ditembus oleh benda-benda tajam. Efek musik menjadi bagian terpenting yang menguatkan daya spiritualitas pelaku hingga sampai pada kondisi trance dalam menjalani ritual sakral keagamaan berupa ritus tindik tubuh -- sebagai wujud rasa syukur, penyucian diri dalam menunaikan nazar.

Penelitian ini sangat penting dilakukan di tengah minimnya kajian tentang kebudayaan musik pada kelompok etnis Hindu Tamil di beberapa daerah di Indonesia, khususnya di Banda Aceh. Penelitian ini juga nantinya akan menyoroti aspek pengaruh dan fungsi musik dalam upacara perayan Ritual Thaipusam, terutama fungsinya terhadap dalam penyelenggaraan upacara maupun pengaruhnya terhadap spiritualitas pelaku ritual yang terbangun saat menjalani ritus-ritus sakral yang cukup ekstrim.

Kajian ini juga akan mengamati konteks ritual keagamaan etnis Hindu Tamil di daerah yang mayoritas masyarakat beragam Islam dengan penerapan hukum syariat yang cukup ketat. Maka, penelitian ini merumuskan permasalah di antaranya: bagaimana fungsi musik dalam upacara ritual Thaipusam di Banda 
Gorga : Jurnal Seni Rupa

Volume 10 Nomor 02 Juli-Desember 2021

p-ISSN: 2301-5942 | e-ISSN: 2580-2380

Aceh, dan bagaimana pengaruh musik terhadap spiritualitas peserta ritual.

\section{KAJIAN TEORI}

Buku berjudul "Music and Trance" yang ditulis oleh Gilbert Rouget (1980), menjelaskan bentuk-bentuk musik dan instrumen musik yang sangat memengaruhi kondisi psikologis pendengarnya dalam mencapai tingkat kekusyukan tertentu, bahkan sampai pada kondisi trance. Referensi ini nantinya akan berguna dalam melihat peran dan fungsi musik dalam upacara perayaan Thaipusam dan bagi peserta ritual di dalamnya.

Guna mendukung referensi di atas, kajian ini juga akan dilengkapi dengan pendekatan teori fungsi musik dalam bukunya The Anthropology of Music. Merriam berpendapat bahwa, ada sepuluh fungsi musik dalam studi etnomusikologi yaitu: (1) fungsi pengungkapan emosional; (2) fungsi pengungkapan estetika; (3) fungsi hiburan; (4) fungsi komunikasi; (5) fungsi perlambangan; (6) fungsi reaksi jasmani; (7) fungsi yang berkaitan dengan norma sosial, (8) fungsi pengesahan lembaga sosial; (9) fungsi kesinambungan kebudayaan; dan (10) fungsi pengintegrasian masyarakat (Merriam \& Merriam, 1964).

Selain itu, Merriam membedakan pengertian fungsi dan guna atau penggunaan musik. Penggunaan menunjukkan situasi musik yang dipakai dalam kegiatan manusia, sedangkan fungsi berkaitan dengan alasan mengapa si pemakai melakukan, dan terutama tujuan-tujuan yang lebih jauh dari sekedar apa yang dapat dilayaninya. Merriam menekankan bahwa penggunaan lebih berkaitan dengan sisi praktis, sedangkan fungsi lebih berkaitan dengan sisi integrasi dan konsistensi internal budaya (Merriam, 1964).

Menurutnya, membedakan pengertian penggunaan dan fungsi adalah sangat penting. Para ahli etnomusikologi pada masa lampau tidak begitu teliti terhadap perbedaan ini. Jika kita berbicara tentang penggunaan musik, maka kita menunjuk kepada kebiasaan (the ways) musik dipergunakan dalam masyarakat, sebagai praktik yang biasa dilakukan, atau sebagai bagian dari pelaksanaan adat istiadat, baik ditinjau dari aktivitas itu sendiri maupun kaitannya dengan aktivitas-aktivitas lain (Merriam \& Merriam, 1964). Merriam membedakan konsep penggunaan dan fungsi musik berdasarkan kepada tahap dan pengaruhnya dalam sebuah masyarakat. Musik dipergunakan dalam situasi tertentu dan menjadi bagian dari stuasi tersebut. Penggunaan bisa atau tidak bisa menjadi fungsi yang lebih dalam.
Penelitian ini akan melihat fenomena kebudayaan musik dan ritual keagamaan etnis Hindu Tamil di Banda Aceh, serta melihat peran dan fungsi musik, khususnya terhadap perilaku peserta ritual. Penelitian ini dirasa penting karena sejauh ini belum terdapat literatur hasil kajian yang membahas fenomena musik dalam upacara perayaan Ritual Thaipusam di Banda Aceh, maupun di beberapa tempat lain. Hasil penelitian-penelitian sebelumnya hanya terfokus pada aspek ritual dan konteks perayaan Thaipusam itu sendiri.

\section{METODE PENELITIAN}

Metode penelitian pada umumnya terbagi kepada dua metode yang lazim digunakan yaitu metode penelitian kualitatif dan metode penelitian kuantitatif. Penelitian ini nantinya menggunakan metode penelitian kualitatif. Penelitian kualitatif didefinisikan sebagai prosedur yang menghasilkan data deskriptif berupa kata-kata tertulis atau lisan dari orang-orang dan perilaku yang dapat diamati (Moleong, 2007). Untuk mendukung metode penelitian kualitatif sebagai metode penelitian yang telah dipilih, maka juga dilakukan beberapa tahapan penelitian. Adapun beberapa tahapan sesuai dengan dikemukakan oleh Bogdan. Ia menyajikan tiga tahapan dalam melakukan proses penelitian kualitatif, yaitu: (1). Pralapangan; (2). Kegiatan lapangan; (3). Dan analisis intensif (Moleong, 2007).

Tahap pra lapangan ini berbentuk studi literatur dan studi dokumentasi yang menjadi langkah awal dalam melakukan suatu penelitian pada tahap ini. Studi literatur dan studi dokumentasi sangat berguna untuk mengetahui apakah objek serta permasalahan yang akan diteliti ini sebelumnya sudah diteliti sebelumnya. Tahapan ini akan diawali dengan mengumpulkan referensi-referensi berupa buku, artikel jurnal, dan sumber tertulis yang berkaitan dengan upacara ritual Thaipusam.

Langkah selanjutnya adalah tahap kerja lapangan untuk mengumpulan data yang akan dianalisis menjadi sebuah bentuk laporan. Dengan melakukan studi lapangan yaitu pengumpulan data-data dengan cara melakukan observasi, wawancara serta pendokumentasian yang mengunakan alat dokumentasi seperti kamera foto, kamera vidio dan alat perekam berupa handphone.

Terkait dengan pentingnya langkah observasi (pengamatan) dalam setiap penelitian. Penulis dalam hal ini akan mengamati beberapa dokumentasi audio vidio penyelanggaraan upacara ritual Thaipusam di Kota Banda Aceh. Gunanya sebagai pendukung 




perumusan masalah dan mengidentifikasian objek yang akan diteliti. Selain itu, juga untuk memperoleh data primer guna mendukung data-data yang didapat dari studi literatur dan studi dokumentasi pada tahap pra lapangan, sekaligus untuk meminimalisir keraguan agar tidak terjadinya bias data yang diperoleh sebelum penelitian lewat studi pustaka yang dilakukan.

Proses dalam tahap wawancara akan dilakukan dalam bentuk tanya jawab antara penulis dan informan yang berkaitan langsung dengan objek yang diteliti. Narasumber yang penulis temui adalah orang-orang yang terlibat langsung di dalam upacara ritual Thaipusam. Salah satunya adalah Krisna (55), yang merupakan pendeta di kuli Palani Andawer. Proses wawancara dilakukan dengan tujuan agar penulis mendapatkan data-data yang akurat tentang objek penelitian ini nantinya.

Proses pendokumentasi sangat penting gunanya untuk membantu melengkapi data-data sebagai penunjang suatu penelitian dalam tahapan lanjutan analisis dan pengolahan data yang didapat di lapangan nantinya. Proses pendokumentasian mengunakan instrumen penelitian. Tahapan ini dilakukan dengan memanfaatkan kamera foto, kamera vidio, dan alat perekam audio berupa handphone. Berhubung pada saat ini tidak diselenggarakannya perayaan ritual Thaipusam oleh etnis Hindu Tamil yang berdomisili di kota Banda Aceh, maka, pendokumentasian hanya dilakukan pada aktivitas keagamaan di kuil Palani Andawer.

\section{HASIL DAN PEMBAHASAN}

\section{Hasil}

"Guna" mengacu pada situasi di mana musik digunakan dalam tindakan manusia; sedangkan "fungsi" menyangkut alasan penggunaannya dan khususnya tujuan yang lebih luas yang dilayaninya. (Merriam \& Merriam, 1964). Aspek guna yang dijelaskan Merriam pada bukunya The Antropologi of Music, yaitu, hal-hal yang peran musik tampak jelas pada suatu konteks kebudayaan di mana musik itu dihadirkan. Sebagai contoh, suatu musik yang terdengar riuh, menandakan sedang dilangsungkan helat pada suatu suatu titik lokasi. Sedangkan aspek fungsi, adalah hal-hal yang lebih luas dari aspek guna. Sebagai contoh, musik tertentu menjadi penanda terhadap prestise sosial seseorang maupun sekelompok orang di tengah masyarakat.

Merriam berpendapat, sebagiamna yang telah disebutkan pada bagian sebelumnya, bahwa, ada sepuluh fungsi musik dalam studi etnomusikologi
Gorga : Jurnal Seni Rupa

Volume 10 Nomor 02 Juli-Desember 2021 p-ISSN: 2301-5942 | e-ISSN: 2580-2380

yaitu: (1) fungsi pengungkapan emosional; (2) fungsi pengungkapan estetika; (3) fungsi hiburan; (4) fungsi komunikasi; (5) fungsi perlambangan; (6) fungsi reaksi jasmani; (7) fungsi yang berkaitan dengan norma sosial, (8) fungsi pengesahan lembaga sosial; (9) fungsi kesinambungan kebudayaan; dan (10) fungsi pengintegrasian masyarakat (Merriam \& Merriam, 1964). Kesepuluh fungsi musik yang dikemukakan Merriam adalah fungsi musik dalam konteks kebudayaan dan masyarakat pada umumnya. Namun, juga terdapat fungsi-fungsi lain yang melingkupi keberadaan musik dalam suatu konteks sosial maupun budaya.

Keberadaan musik dalam konteks upacara perayaan Ritual Thaipusam memiliki dua fungsi, yaitu, fungsi musik dalam upacara ritual dan fungsi musik terhadap peserta ritual, dalam hal ini orang yang sedang melakukan nazar atau orang-orang yang menjadikan ritual tersebut sebagai sarana untuk melepas nazar.

\section{Pembahasan}

\section{1). Fungsi Musik dalam Ritual Thaipusam}

Musik yang digunakan dalam upacara perayaan Ritual Thaipusam di Banda Aceh adalah jenis musik ensambel perkusi yang terdiri dari beberapa jenis alat musik, di antaranya: gendang yang memiliki satu sisi membran, jenis vessel drum dan gendang yang memiliki dua sisi membran, jenis silindrical drum. Dalam ensambel musik perkusi tersebut terdiri satu sampai dua buah vessel drum berbentuk tansa berukuran kecil dan sedang, serta delapan hingga belasan buah silindical drum berupa gendang berukuran kecil, sedang, hingga besar, tergantung pada ketersedian dan komposisi alat musik dari kelompok gendrang yang diundang pada upacara perayaan tersebut.

Beberapa jenis alat musik membranophone dalam ensambel perkusi dalam upacara perayaan Ritual Thaipusam dimainkan dengan cara dipukul. Untuk instrumen berjenis vessel drum, menggunakan dua buah rotan. Sedangkan untuk instrumen berjenis silindical drum menggunakan dua buah stick kayu sebagai alat pemukul membran dari masing-masing alat musik tersebut.

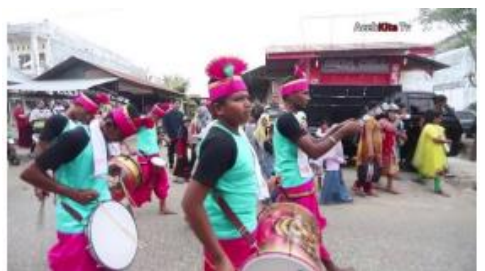

Gambar 1. Kolompok Ensambel Perkusi pada Upacara Perayaan Ritual Thaipusam di Banda Aceh (AcehKita, 2018) 
Keseluruhan alat musik perkusi tersebut disandang dan berada pada bagian depan tubuh masing-masing pemain. Dalam formasi ensambel musik perkusi tersebut juga disertakan seorang pembawa lagu yang melantunkan nyanyian religius dan lagu-lagu keagamaan Hindu yang bertemakan tentang dewa Murugan, yang disebut parita (wawancara dengan Radha Krishna, Juli 2021, di Banda Aceh).

Musik perkusi dilibatkan pada bagian prosesi arakarakan dalam upacara perayaan ritual Thaipusham. Prosesi arak-arakan dilangsungkan pada waktu malam pada hari pertama perayaan dan siang hari pada hari kedua. Biasanya, prosesi arak-arakan berlangsung selama 1-2 jam. Prosesi ini dilaksanakan dengan cara berjalan kaki untuk berkeliling di jalan sekitar kuil Palani Andawer.

Prosesi arak-arakan bertujuan membawa keluar arca Dewa Murugan untuk diarak keliling kawasan sekitar kuil Palani Andawer di Kota Banda Aceh. Aktivitas arak-arakan arca Dewa Murugan juga bertujuan mengeluarkan aura positif yang ada pada arca Dewa Murugan yang diyakini oleh etnis Hindu Tamil agar terhindar dari bencana. Selain itu, sebagaimana yang telah disebutkan sebelumnya, bahwa prosesi ini juga sebagai wadah untuk para penazar untuk melakukan praktik menunaikan nazar.

Kelompok ensambel perkusi gendang yang mengiringi prosesi arak-rakan arca Dewa Murugan adalah kelompok-kelompok gendang yang didatangkan dari daerah Medan dan sekitarnya. Biasanya, setiap tahunnya, akan didatangkan kelompok yang berbeda. Pengurus kuil Palani Andawer mendatangkan secara bergantian setiap tahun kelompok gendang dari daerah Kebun Bunga, Sunggal, Lubuk Pakam, dan sebagainya. Hal ini bertujuan untuk mempererat hubungan persaudaraan dan komunikasi antara kelompok etnis Hindu Tamil di Banda Aceh dengan kelompok etnis Hindu Tamil yang tersebar di berbagai daerah di Kota Medan dan sekitarnya.

Musik ensambel perkusi yang dimainkan pada saat prosesi arak-arakan arca Dewa Murugan memiliki beberapa fungsi dalam konteks penyelenggaraan upacara perayaan Ritual Thaipusam, maupun bagi peserta nazar yang mengikuti prosesi ritual tersebut. Jika dilihat dari aspek fungsional, terdapat empat fungsi musik dalam upacara perayaan Ritual Thaipusam, di antaranya: (1). Fungsi Pemeriah dan Hiburan; (2). Fungsi Ekspresi Sosial dan Budaya; (3) Fungsi
Pengabsahan Upacara Ritual; (4) Fungsi Integritas Kelompok Masyarakat.

\section{(1). Fungsi Pemeriah dan Hiburan}

Ritual Thaipusam diselenggarakan untuk penyucian diri sekaligus untuk penghormatan serta merayakan hari kemenangan Dewa Murugan yang telah berhasil menumpas kejahatan denga cara mengalahkan asura (iblis). Ritual tersebut juga sebagai momentum pemujaan terhadap Dewa Murugan yang dikenal sebagai dewa perang, dewa kejayaan, dan dewa pelindung negeri Tamil. Sebagian kalagan menyebutkan bahwa, penyelengaraan upacara perayaan ritual tersebut merupakan perayaan atas kelahiran Dewa Murugan. Mitologi ini berkembang dalam cerita rakyat dalam bentuk epos di kalangan etnis Hindu Tamil di dunia, pada umumnya.

Prosesi arak-arakan pada upacara perayaan Ritual Thaipusam merupakan wujud dan cerminan kegembiraan atas kemenangan Dewa Murugan. Setiap peserta yang mengikuti arak-arakan dengan perasaan gembira dan suka cita. Pada prosesi arakarakan, fungsi ensambel gendang adalah untuk pemeriah dan menciptakan suasana riuh dan meriah. Di samping itu, musik juga bersifat menghibur semua perserta arakarakan yang mengiringi arakan arca Dewa Murugan. Biasanya, setiap perserta yang bergabung dalam rombongan prosesi arak-arakan, akan menari dan bernyanyi mengikuti nyanyian keagaaman yang dilantunkan oleh pembawa lagu yang tergabung dalam kelompok ensambel perkusi gendang.

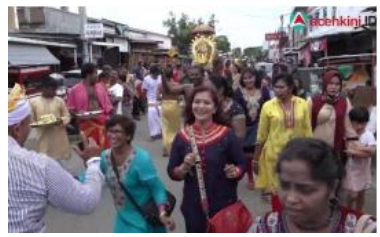

Gambar 2. Peserta Ritual Sedang Menari pada Prosesi Arakarakan (Acehkini, 2019)

Pada umumnya, rombongan arak-arakan terdiri dari pendukung upacara di antaranya, pendeta, panitia yang mengusung mahligai yang berisikan duplikat arca Dewa Murugan dan tunggangannya, bhakta atau undangan khusus yang merupakan etnis Tamil yang datang dari berbagai daerah di dalam maupun luar negeri, kemudian peserta nazar.

\section{(2). Fungsi Ekspresi Budaya}

Musik cenderung dianggap sebagai wahana ekspresi personal maupun kelompok pada suatu masyarakat. Etnis Tamil yang mayoritas bergama Hindu, merupakan bagian dari masyarakat India yang telah 
Gorga : Jurnal Seni Rupa

Volume 10 Nomor 02 Juli-Desember 2021

p-ISSN: 2301-5942 | e-ISSN: 2580-2380

berdiaspora ke berbagai negara di dunia, termasuk di kawasan Asia Tenggara. Tradisi musik bagi masyarakat India telah melekat sejak lama, baik ke dalam kehidupan sekuler maupun keagamaannya.

Sebagaimana yang disampaikan di atas, bahwa fungsi musik sebagai pemeriah. Keberadaan musik dalam upacara perayaan Ritual Thaipusam adalah untuk menciptakan suasana meriah. Tentunya, konteks ini didukung oleh hadirnya jenis-jenis musik tertentu pada konteks upacara tertentu pula. Jika upacara menyangkut keagamaan, maka musik yang hadir di dalamnya bertemakan keagaamaan, begitu sebaliknya, jika konteksnya kegiatan sekuler, maka yang dihadirkan adalah musik-musik yang bertemakan sekuler.

Kelompok ensambel musik perkusi yang dihadirkan dalam upacara perayaan Ritual Thaipusam adalah manifestasi sekaligus reinterpretasi secara simbolis sebuah bentuk suka cita yang dikemas dalam bentuk perayaan yang bersifat keagamaan yang dilangsungkan oleh etnis Hindu Tamil setiap tahunnya. Sebagai sebuah perayaan keagamaan yang besar dan sakral, upacara perayaan Ritual Thaipusam tentunya membawa spirit kemenangan yang tercermin dalam ritmis musik perkusi dan nyanyian yang mengagungkan Dewa Murugan. Tampak jelas dalam konteks ini, musik berfungsi sebagai media untuk mengekspresikan budaya bagi etnis Hindu Tamil, terutama pada saat penyelenggaraan Thaipusam.

\section{(3). Fungsi Pengabsahan Upacara Ritual}

Kehadiran ensambel musik perkusi dalam salah satu bagian prosesi ritual Thaipusam begitu penting. Bahkan, dapat dikatakan sebagai suatu keniscayaan. Masyarakat india yang mayoritasnya beragama Hindu, termasuk etnis Tamil yang telah menyebar dan berdiaspora dari daerah Tamil Nadu, India Selatan dan Sri Langka ke berbagai daerah di dunia, termasuk di kawasan Asia Tenggara -- selalu menghadirkan unsurunsur musik ke dalam beberapa bentuk peristiwa kebudayaan, termasuk dalam ritual-ritual keagamaan. Bahkan, musik tidak terpisah dari setiap upacaraupacara riligius dan keagaamaan.

Pada perayaan ritual Thaipusam, musik berfungsi sebagai pengabsaan terhadap ritual tersebut. Tanpa kehadiran musik, ritual Thaipusam hanya sebatas ritual sakral keagamaan saja. Oleh karena itu, jika dilihat secara subtansi, ritual Thaipusam - sebagaimana yang disebutkan sebelumnya ---merupakan ritual perayaan atas kemenangan dewa dari etnis Hindu Tamil. Oleh sebab itu, kehadiran ensambel musik perkusi ke dalam rangakian upacara, menjadi sebuah bentuk mengabsahan terhadap ritual Thaipusam yang bersifat perayaan dan kegembiraan tersebut.

\section{(4) Fungsi Integritas Kelompok Masyarakat}

Upacara perayaan Ritual Thaipusam diselenggarakan oleh kelompok etnis Tamil serentak maupun secara bergantian di berbergai daerah di dunia. Di beberapa wilayah di Indonesia, terutama di Provinsi Sumatera Utara dan Aceh, perayaan tersebut diatur oleh organisasi perhimpunan etnis Hindu Tamil yang berlokasi di Medan, yang diselenggarakan dengan cara bergantian bertepatan pada bulan Thai dalam kalender etnis Hindu Tamil, atau sekitar bulan Februari hingga Maret -- setiap tahun pada kalender masehi.

Upacara perayaan Ritual Thaipusam pada beberapa titik lokasi di Kota Medan maupun Kota Banda Aceh, selalu dihadiri oleh tamu undangan atau bhakta maupun individu-individu yang diundang secara khsusu maupun datang secara inisiatif sendiri untuk sekadar mengikuti dan meramaikan kegiatan, serta sebagai bentuk ibadah. Biasanya motivasi untuk datang ke titik lokasi upacara perayaan Ritual Thaipusam didorong oleh alasan ibadah. Maka dari itu, setiap penyelenggaraaan upacara perayaan Ritual Thaipusam selalu dihadiri oleh individu maupun kelompok etnis Hindu Tamil dari berbagai daerah di luar daerah yang melangsungkan upacara perayaan tersebut.

Upacara perayaan Ritual Thaipusam yang diselenggarakan di kuil Palani Andawer di Kota Banda Aceh, pada tahun-tahun sebelumnya relatif ramai dikunjungi oleh individu maupun kelompok Hindu Tamil dari luar Kota Banda Aceh, baik dari dalam maupun luar negeri. Namun, sebagaimana yang telah disebutkan sebelumnya, perayaan keagamaan ini tidak diselenggarakan selama dua tahun terakhir karena kondisi pandemi yang terjadi hampir di setiap daerah di dunia.

Kehadiran musik yang dibawakan oleh kelompok ensambel perkusi pada setiap penyelenggaraan Ritual Thaipusam dapat dikatakan memiliki fungsi pengintegritasan atau penyatuan kelompok etnis Hindu Tamil dari berbagai daerah. Atau dapat diakatakan sebagai wahan pemersatu dalam bentuk perayaan keagamaan -- dikarenakan Ritual Thaipusam tergolong pada upacara menurut hari besar atau upacara keagaaman. Hal ini dapat dilihat, ketika prosesi arakarakan, setiap pendukung ritual berbaur hikmat dalam suasana suka cita merayakan hari kemenangan Dewa Murugan. 


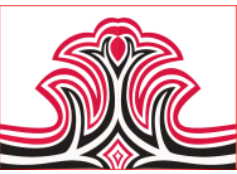

2). Fungsi Musik bagi Peserta Ritual Thaipusam Gilbert Rouget berpandangan bahwa, musik perkusi merupakan instrumen yang paling mudah memengaruhi pendengaran manusia karena memiliki efek neurogikal yang membuat setiap pendengarnya dapat mencapai kondisi khusyuk, bahkan trance (Rouget, 1985). Pandangan Rouget tentang efek musik perkusi secara neorulogis terhadap manusia yang mendengarkannya, dapat digunakan untuk melihat fenomena musik yang berdampak secara tidak langsung terhadap spiritualitas peserta nazar yang mengikuti upacara perayaan Ritual Thaipusam di kuil Pelani Andawer di Kota Banda Aceh, dengan melihat kondisi kekusyukan yang dicapai peserta saat mengikuti prosesi ritual.

Peserta nazar yang terdiri dari beberapa individu dari etnis Hindu Tamil yang melangsungkan nazar pada salah satu prosesi dalam upacara perayaan Ritual Thaipusam adalah orang-orang yang memiliki niat untuk bernazar atas suatu masalah maupun persoalan tertentu, maupun untuk menebus dosa-dosa yang dilakukan selama hidup. Mengikuti prosesi ritual adalah suatu praktik spiritual keagamaan untuk menunaikan atau membayar nazar dari masing-masing individu, sekaligus untuk menyucikan diri.

Nazar dilakukan dalam bentuk praktik tindik tubuh, sebagaimana yang dijelaskan pada bagian sebelumnya, bahwa, tindik tubuh yang dilakoni peserta nazar diterapkan pada bagian tubuh, di antaranya: pada bagian pipi, bibir, lidah, dahi, perut, dan punggung. Alat yang digunakan untuk melakukan praktik tindik tubuh bagi peserta nazar berupa benda-benda tajam berupa jarum dengan berbagai ukuran yang biasa disebut dengan 'vel' dan kail. Vel merupakan simbolisasi kemenangan dewa Murugan dan juga replikasi tongkat, sebagai kalangan menyebutkan anak panah Dewa Murugan yang diberi oleh Dewa Syiwa untuk menumpas kejahatan.

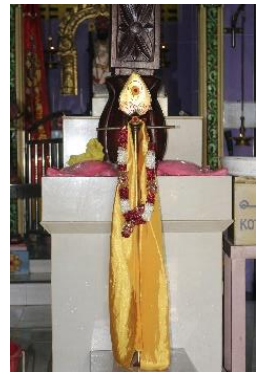

Gambar 3. Vel yang Terdapat pada Kuil Pelani Andawer (Wirandi, 2020)

Sebelum melakukan nazar, sebagaimana yang telah disinggung sebelumnya, bahwa, peserta nazar diwajibkan untuk berpuasa setiap hari, diet vegetarian,
Gorga : Jurnal Seni Rupa

Volume 10 Nomor 02 Juli-Desember 2021 p-ISSN: 2301-5942 | e-ISSN: 2580-2380

dan tidak melakukakan hubungan suami istri. Aktivitas tersebut dijalankan selama beberapa puluh hari sebelum melakukan nazar. Aktivitas ini bertujuan agar calon peserta nazar untuk kembali suci ketika akan melakukan nazar. Selain itu, beberapa aktivitas pra pelaksanaan nazar tersebut merupakan syarat wajib bagi setiap individu yang akan melakukan nazar.

Posisi tindik pada bagian tubuh tertentu, biasanya tergantung pada niat, kemauan, serta kesanggupan peserta ritual. Biasanya, bagi peserta nazar yang baru pertama kali melakukan nazar dan tindik tubuh akan disarankan untuk menindik pada bagian lidah, bibir, dan pipi dengan menggunakan jarum yang relatif kecil. Namun, menurut Radha Krisnha, ada juga peserta pemula yang menyanggupi untuk melakukan praktik tindik tubuh dengan jarum yang berukuran besar, bahkan menyanggupi praktik tindik berupa pemasangan benda berbentuk kail tajam dalam jumlah yang cukup banyak pada bagian punggung (wawancara dengan Radha Krisnha, April 2021, di Banda Aceh).

Benda-benda tajam yang digunakan untuk praktik tindik tubuh peserta ritual, dipasangkan langsung oleh para pendeta dan panitia ritual. Pemasangan dilakukan dilakukan di dalam kuil sebelum melakukan prosesi arak-arakan. Proses pemasangan tindik tubuh tersebut, dilakukan oleh pendeta dengan pembacaan mantramantra tertentu. Selain itu, nyanyian keagamaan tetap dilantunkan yang diiringi oleh ensambel musik perkusi gendang. Begitupun pada saat mengikuti prosesi arakarakan yang berlangsung selam satu jam, bahkan lebih. Suara musik dan lantunan nyanyian keagamaan yang kebanyakan bertemakan tentang kisah Dewa Murugan -- mendampingi peserta berjalan dari titik awal prosesi arak-arkan di sekitar kuil hingga kembali ke kuil.

Pada saat proses pemasangan jarum maupun kail pada beberapa bagian peserta ritual hingga selesai, hampir tidak terjadi pendaharan. Menurut Radha Krishna yang juga pernah menjadi peserta nazar dan melakukan praktik tindik tubuh sekitar tahun 2014 lalu, pada saat pemasangan benda-benda tersebut menancap dalam waktu yang cukup lama -- ia sama sekali tidak merasakan sakit ketika benda-benda tajam yang berukuran cukup besar tersebut tertancap di bagian pipi kiri hingga menembus pipi kanannya (wawancara dengan Radha Krisnha, Juli 2021, di Banda Aceh).

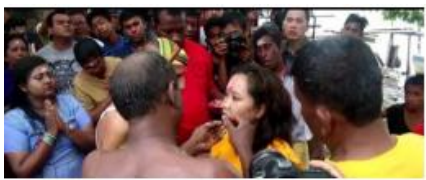


Gambar 4. Proses Pemsangan Jarum untuk Tindik Tubuh bagi Peserta Nazar dalam Upacara Ritual Thaipusam di Banda Aceh (Ananda, 2016).

Musik ensambel perkusi dan nyanyian religius keagamaan pada prosesi arak-arakan arca Dewa Murugan pada upacara perayaan Ritual Thaipusam berfungsi membangun spirit dan secara spiritual sebagai penguatan untuk mengantar peserta pada kondisi yang lebih khusyuk dalam menunaikan nazar. Musik tersebut diyakini oleh peserta ritual mampu menguatkan mental dan spiritual sebagai proses menyucikan diri. Musik juga berperan mengantarkan peserta ritual masuk pada kondisi yang membayangkan kekuatan dan kemenangan Dewa Murugan menumpas kejahatan.

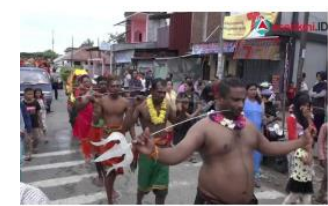

Gambar 5. Beberapa Peserta Nazar dengan Tindik Tubuh Sedang Mengikuti Prosesi Arak-arakan dalam Upacara Ritual Thaipusam di Banda Aceh (Acehkini, 2019)

Perayaan Thaipusam melambangkan kemenangan atas diri kita dari dalam maupun luar, sifat-sifat yang tidak baik seperti nafsu, amarah, iri hati, cemburu, dan lainlain. Sedangkan dari luar adanya bencanabencana alam, kekuatan maupun kejahatankejahatan yang dapat menghancurkan kita sebagai wujud nyata Dewa Murugan melintas, akan memberikan penerangan, kesejahteraan, kemakmuran, serta kedamaian (Karnaen, 2017).

Spirit kemenangan Dewa Murugan juga dapat direinterpretasikan kepada bentuk kemenangan atas sesuatu yang tidak baik yang ada dalam setiap individu, terutama bagi individu yang menjadi peserta nazar. Kondisi ini menjadi pendorong kekusyukan peserta ritual dalam menjalani prosesi ritual untuk menunaikan nazar mereka. Kekuatan lain yang bisa membantu peserta masuk ke dalam dimensi spiritual adalah doadoa, nyanyian, serta musik yang mengiringi selama prosesi arak-arakan dan nazar berlangsung.

\section{KESIMPULAN DAN SARAN}

\section{Kesimpulan}

Secara keseluruhan, ensambel musik perkusi memiliki fungsi yang kompleks dalam upacara perayaan Ritual Thaipusam. Hal tersebut bisa dilihat dari peranannya dalam bagian prosesi arak-arakan Dewa Murugan. Prosesi tersebut juga menjadi sarana bagi pendukung ritual yang menjadi peserta nazar.
Gorga : Jurnal Seni Rupa

Volume 10 Nomor 02 Juli-Desember 2021

p-ISSN: 2301-5942 | e-ISSN: 2580-2380

Setidaknya terdapat empat fungsi musik yang teramati dalam penelitian ini, di antaranya: fungsi pemeriah dan hiburan; fungsi ekspresi budaya; fungsi pengabsahan upacara ritual; dan fungsi integritas kelompok masyarakat. Di sisi lain, bagi pendukung ritual - dalam hal ini peserta nazar, musik berfungsi sebagai penguat spiritual mereka dalam menunaikan nazar.

\section{Saran}

Sebagai peneliti, saya menyarankan agar generasi muda komunitas etnis Hindu Tamil di Kota Banda Aceh memiliki keinginan untuk membentuk dan belajar menguasai ensambel gendang perkusi pengiring prosesi arak-arakan dalam upacara perayaan Ritual Thaipusam, agar tidak penyelenggaraan Thaipusam tidak lagi direpotkan untuk mengundang kelompok gendang dari luar Kota Banda Aceh.

\section{DAFTAR RUJUKAN}

AcehKita. (2018). Perayaan Maha Puja Pengguni Uthiram, Umat Hindu Tamil di Aceh. YouTube. https://www.youtube.com/watch?v=q1rwc294N wA.

Acehkini. (2019). Prosesi Arakarakan. YouTube. Acehkini.id/https://www.youtube.com/watch?v= plj926dKupo.

Ananda, Ferdian. (2016). Uthiram Pangguni Celebration in Aceh. YouTube. https://www.youtube.com/watch?v=L77hKkVZ7 $\mathrm{xA}$.

Dwi, N. (2019). Festival Thaipusam Sebagai Daya Tarik Wisata di Batu Caves Malaysia.

Karnaen, Y. (2017). Analisis Tari Bharatanatyam dan Musik Iringan pada Upacara Thaipusam Masyarakat Tamil di Kota Binjai.

Merriam, A. P., \& Merriam, V. (1964). The Anthropology of Music. Evanston: Northwestern University Press.

Mogot, Y. (2019). Aktivitas Komunikasi Masyarakat Hindu Tamil Dalam Upacara Thaipusam Di Singapura. Jurnal Common, 3(2), 216-228.

Moleong, L. J. (2007). Metodologi Penelitian Kualitatif Edisi Revisi. Bandung : PT Remaja Rosdakarya.

Riyaf, A., \& Hasanah, N. (2016). Anthropos: Jurnal Antropologi Sosial dan Budaya. Anthropos, 2(1), 46-61.

Rouget, G. (1985). Music and Trance: A Theory of the Relations Between Music and Possession. Chicago: University of Chicago Press.

Wirandi, Rika. (2020). "Vel yang Terdapat pada Kuil Pelani Andawer". Hasil Dokumentasi Pribadi: 09 Juni 2020, Banda Aceh. 